\title{
Perceived Changes in Sexual Interest and Distress About Discrepant Sexual Interest During the First Phase of COVID-19 Pandemic: A Multi-Country Assessment in Cohabiting Partnered Individuals
}

\author{
Aleksandar Štulhofer ${ }^{1}$ (D) Jasmina Mehulić ${ }^{2} \cdot$ Peer Briken $^{3} \cdot$ Kateřina Klapilová $^{4} \cdot$ Hanneke de Graaf $^{5}$. \\ Ana Alexandra Carvalheira ${ }^{6}$. Charlotta Löfgren-Mårtenson ${ }^{7} \cdot$ Pedro Nobre $^{8} \cdot$ Marie Chollier $^{9} \cdot$ Özlem Köse $^{10}$. \\ Eva Elmerstig ${ }^{11}$. Christophe Lançon ${ }^{12} \cdot$ Leona Plášilová $^{4} \cdot$ Johanna Schröder ${ }^{3,13}$
}

Received: 11 October 2020 / Revised: 2 December 2021 / Accepted: 22 December 2021 / Published online: 17 January 2022

(c) The Author(s), under exclusive licence to Springer Science+Business Media, LLC, part of Springer Nature 2022

\begin{abstract}
Due to COVID-19 pandemic, different restrictive measures in terms of physical distancing and lockdowns have been introduced in most European countries, affecting all facets of social life. Currently, little is known about how partnered individuals perceive changes in their sexual life during this complex emergency. This study explored retrospectively assessed changes in sexual interest for one's partner and levels of distress related to perceived sexual interest discrepancy during the first phase of the pandemic in a large-scale online sample of partnered individuals $\left(n=4813 ; M_{\text {age }}=38.5\right.$ years, $\left.\mathrm{SD}=10.74\right)$ recruited between May and July 2020 in seven European Union countries and Turkey. We also examined the possible role of approach/ avoidance motives for sex in reported changes in sexual interest and associated distress. Most participants (53\%) reported no change in their sexual interest during the pandemic, followed by those who reported an increase (28.5\%). The pattern was similar across the eight countries. Distress about discrepant sexual interest, which was only weakly related to changes in sexual interest, was significantly associated with relationship quality and emotional closeness with a partner, coping with and worrying about the pandemic, and specific motivation for sex. In contrast to avoidant and relationship-focused approach motivation, ego-focused approach motivation was related to stable sexual interest during the pandemic. The current study contributes to the understanding of the link between sexual interest and complex emergencies. Considering that the COVID19 pandemic continues, the reported experiences and perceptions are prone to change.
\end{abstract}

Keywords Sexual interest discrepancy · Sexual distress · COVID-19 · Complex emergency $\cdot$ Approach/avoidance sexual motivation

Aleksandar Štulhofer

astulhof@ffzg.hr

1 Department of Sociology, Faculty of Humanities and Social Sciences, University of Zagreb, I. Lučića, 10000 Zagreb, Croatia

2 Department of Psychology, Faculty of Humanities and Social Sciences, University of Zagreb, Zagreb, Croatia

3 Center for Psychosocial Medicine, Institute for Sex Research, Sexual Medicine and Forensic Psychiatry, University Medical Center Hamburg-Eppendorf, Hamburg, Germany

4 National Institute of Mental Health, Klecany, Czech Republic

5 Rutgers, Utrecht, The Netherlands

6 ISPA-University Institute of Psychology and Social Sciences, Lisbon, Portugal
7 Department of Social Work, Malmö University, Malmö, Sweden

8 Faculty of Psychology and Educational Sciences, University of Porto, Porto, Portugal

9 Assistance Publique Hôpitaux de Marseille, Marseilles, France

10 Private Practice, Montréal, PQ, Canada

11 Centre for Sexology and Sexuality Studies, Department of Social Work, Malmö University, Malmö, Sweden

12 CEReSS-Health Services and Quality of Life Research, Aix-Marseille University, Marseilles, France

13 Department of Psychology, Medical School Hamburg, Hamburg, Germany 


\section{Introduction}

The COVID-19 pandemic resulted in unprecedented global changes to daily life, both in public and private domains, affecting social life (Morris, 2020), economic activity (Fernandes, 2020), and psychological health (Pfefferbaum \& North, 2020). What makes this present crisis particularly challenging is the fact that there is no reliable narrative about its future dynamics, and even the optimism based on effective vaccines that may soon be available could be marred by increasing vaccine hesitancy (Lane et al., 2018). The novelty and gravitas of this global disruption have spurred research activity, including studies focusing on reproductive and sexual health in times of the pandemic. Considering that complex crises, such as the current pandemic, have adverse effects on mental health-which are commonly expressed through the increased prevalence of depression and anxiety symptoms (Bendau et al., 2020; Zhang et al., 2020)—the way they affect sexuality might be comparable (see Ibarra et al., 2020).

Apart from focusing on the reduction of reproductive health and rights (Miranda et al., 2020), increase in (mostly) domestic sexual aggression and violence (Mazza et al., 2020; Roesch et al., 2020; Usher et al., 2020), disruption in sexual health services and increasing difficulties in accessing them (Aversa \& Jannini, 2020; Miranda et al., 2020), and risks of sexual transmission of SARS CoV-2 viral infection (Turban et al., 2020), the emerging literature on the pandemic and sexuality also explored potential changes in sexual behavior and sexual well-being (Brotto et al., 2021; Carvalho et al., 2021; Lehmiller et al., 2021). The current study aims to contribute to this developing body of knowledge about human sexuality under complex emergency circumstances by focusing on retrospectively assessed changes in sexual interest and sexual distress among individuals living with their partner. ${ }^{1}$ To explore these issues in cross-cultural context, we used data collected in seven EU countries and Turkey.

\section{Complex Emergencies and Human Sexual Response}

According to the World Health Organization (Wisner \& Adams, 2002), complex emergencies are marked by two main characteristics: people's life and well-being have to be substantially disrupted and existential threats widely perceived and non-institutional responses to the emergency need to be taking place under difficult political and security conditions. The COVID-19 global humanitarian emergency seems to be

\footnotetext{
1 The affect of pandemic-related lockdowns and other restrictions on the sexual life of single women and men (as well as partnered inviduals who do not live together with their partner) has been recently discussed elsewhere (Lopes et al., 2020).
}

characteriyed by both. The sociopolitical dimension features prominently in the "disaster response" phase, which ranged from lockdowns of different severity to various ordinances aimed at regulating daily life. Political and security components should also not be overlooked (Kavanagh \& Singh, 2020); mostly in response to public health measures introduced to curb the pandemic, demonstrations and mass protests have been reported in a number of countries.

When sexuality is discussed in the literature on complex emergencies and ensuing humanitarian crises, issues such as reproductive health risks, HIV, and sexual violence feature prominently (Khaw et al., 2000; Wisner \& Adams, 2002). Similarly, research on COVID-19 and sexuality-related phenomena focused primarily on reproductive health needs and domestic sexual violence. Studies investigating possible changes in sexual interest and sexual expression during the pandemic are still rare (Döring, 2020), which should not be surprising given funding priorities associated with complex emergencies (Albala-Bertrand, 2000; Bedford et al., 2020; Holmes et al., 2020).

\section{The Pandemic and Sexual Interest}

Complex emergencies are reflected in acute sense of fear, uncertainty and vulnerability, elevated levels of stress, and temporarily reduced well-being in affected individuals (Pfefferbaum \& North, 2020; Wisner \& Adams, 2002). This clearly resembles COVID-19 related burdens, such as having to stay at home, being concerned about health and fearing contagion, experiencing economic hardship and facing uncertain future, worrying about older parents, and being overwhelmed with children's education (Prime et al., 2020). Considering the well-established negative link between stress and anxiety on the one hand and sexual interest on the other hand (Carvalheira et al., 2014; Ferreira et al., 2014), the current pandemic's potential to affect sexual interest in partnered individuals is an important issue to explore, both in the context of relationship quality and stability (Schoenfeld et al., 2017; Sprecher \& Cate, 2004), and individual well-being.

Our cursory review of literature-for a more systematic, but wider-reaching overview see Döring (2020)—identified a few empirical studies (carried out in Chinese, Italian, Portuguese, Canadian, and Turkish samples) that explored the pandemic-related changes in sexual desire. An Italian study included 89 partnered women (median age $=39$ years) from a clinical sample and compared their FSFI (Female Sexual Function Index) scores before and after the beginning of the pandemic (Schiavi et al., 2020). Composite scores on FSFI domains of desire, arousal, orgasm, and satisfaction were all substantially lower at the second assessment. Another comparable and similarly low powered Turkish online survey ( $n=58$ women, $M_{\text {age }}=28$ years) found a reduction in the FSFI scores-except for the desire domain (Yuksel \& 
Ozgor, 2020). Two Chinese studies also used online samples of partnered and single individuals (G. Li et al., 2020, W. Li et al., 2020). In both studies, a great majority of participants $(>70 \%)$ were living with their parents. In the larger of the two ( $n=967$, age range $=15-35 ; 56 \%$ of men), $22 \%$ of participants retrospectively reported, among other changes in their sexual life, a decrease in sexual desire. Finally, in the first of two more recent studies, sexual desire domain scores were urrelated to the pandemic-related physical confinement but were significantly (and positively) associated with psychological adjustment in a non-probability-based sample of Portuguese women and men (Carvalho et al., 2021). In a longitudinal study carried out from April to August 2020 using a large-scale sample of partnered and single Canadians, Brotto et al. (2021) reported, somewhat unexpectedly, a link between COVID-19-related distress levels and increased dyadic sexual desire-domonstrating that stressful reactions to the pandemic need not always stifle interest in partnered sex.

To summarize, there is insufficient evidence for any conclusion regarding the association between the pandemic and sexual interest in partnered individuals. Both decrease and increasea in sexual interest have been observed in a handful of study characterized by diverse methodological approaches.

\section{Motives for Sex as a Clue to Changes in Sexual Interest in Complex Emergency Situations?}

Building on the distinction between appetitive and aversive basic response systems (see Gable, 2006), the ApproachAvoidance Motivation Model (AAMM) posits that approach and avoidance represent two relatively independent sets of motives; the former characterized by stronger reactions, even bias, to positive cues (incentives, rewards) and the latter marked by stronger reactions to negative cues (threats, costs). Apart from being theorized as the evolutionary core of the affective system (Cacioppo \& Berntson, 1999), approach and avoidance are seen as distinct dispositional preferences (Elliot et al., 2006) and self-regulatory models (Gable \& Impett, 2012) that are sensitive to circumstances and personal experience (Elliot et al., 2006; Gable, 2006). This situational aspect is important - particularly in the context of the current pandemic - because it can qualify avoidant, but also approach, motives as (dys) functional.

In a number of studies, the AAMM has been linked to achievement, health outcomes, relationship quality, and wellbeing (Elliot et al., 2006; Gable, 2006; Gable \& Impett, 2012; Gable \& Poore, 2008). For example, approach-motivated sacrifices in the context of a committed relationship (aimed at partner's benefit or happiness) were associated with personal well-being and relationship quality over time, while avoidance-motivated sacrifices (made to avoid conflicts and strained relations) had opposite effects (Impett et al., 2005a).
The model has also been successfully applied to the study of sexuality (Gewirtz-Meydan \& Ayalon, 2019; Impett et al., $2005 b, 2008)$, particularly in the exploration of motivation for sex (Muise et al., 2013, 2017). For example, in a sample of North American college students, approach motivation for sex, compared to avoidance motives, was associated with a positive change in both personal and couple well-being (Impett et al., 2005b). This was not only the result of the type of participants' motivation, but also of their perception of their partner's motives. Speculating about potential underlying mechanisms, Impett et al. noted that approach motivated individuals are likely to have more positive expectations of sex, to be more focused on pleasurable sensations, more aroused, and to enjoy sex more compared to avoidance motivated individuals who may have difficulties in relaxing and focusing on pleasure-in addition to being more sensitive to and critical about negative moments during sex (see also Gable \& Impett, 2012).

Following Gewirtz-Meydan and Ayalon (2019), we added the personal/interpersonal dimension to the AAMM to enable a further distinction between ego-oriented and relationshiporiented motivation for sex. In the case of ego-oriented motivation, sex is about personal pleasure and sexual selfaffirmation on the approach side, but mostly about avoiding or reducing partner's dissatisfaction on the avoidance side. An example of relationship-oriented motivation would be engaging in sex to increase emotional intimacy and closeness or, in the case of avoidant motivation, engaging in sex to save the relationship. The distinction between ego- and relationship-oriented motives may be somewhat more relevant for partnered women, as suggested in several studies (Gewirtz-Meydan \& Ayalon, 2019; Sanchez et al., 2011).

The current study applied this extended AAMM model to the context of a global emergency, exploring the role of different motives for sex in (retrospectively reported) change in sexual interest during the first pandemic phase. If approach motivation for sex is beneficial to partnered individuals under normal circumstances, it may also be relevant in times of crisis. Can approach motivation, compared to avoidance, protect against a situational decline in sexual interest? Is the personal/interpersonal dimension of the AAMM of any relevance in this context?

\section{Sexual Interest Discrepancy and Related Distress}

Sexual interest is commonly understood to denote a subjective psychological state focused on engaging in sexual activity, which is triggered by internal and/or external stimuli (Nimbi et al., 2020). Sexual interest has been shown to change with age (Træen et al., 2017), and that its maintenance can be challenging in long-term relationships (Mark \& Lasslo, 2018). Nevertheless, sexual interest for the partner remains an important component of relationship satisfaction 
over time (Brezsnyak \& Whisman, 2004), which explains a potential for distress about differences in partners' levels of interest in sex.

Strong approach motivation has been observed to be positively associated with sexual interest (desire). In three repeated measurement studies, individuals who scored high on approach motives also reported higher levels of sexual desire and a lesser decline in desire on days marked by negative relationship dynamics than other participants (Impett et al., 2008). Although it is currently unknown whether stable sexual interest in committed relationships is consistently associated with approach/avoidance motivation for sex, this question may be of particular importance in the context of discrepant sexual interest.

Despite the fact that clinicians see discrepancy in partners' sexual interest as common, fluid, and not necessarily disruptive (using a novel methodological approach, a recent dyadic study found that desire discrepancy was a poor predictor of relationship and sexual satisfaction; Kim et al., 2020), distress about a mismatch in sexual interest seems all but rare among partnered individuals (Dewitte et al., 2020; Herbenick et al., 2014). Distressing discrepancy can result in relationship discord and have a detrimental effect on relationship/marital stability (Schoenfeld et al., 2017). More abrupt changes in partners' levels of sexual desire are more likely to be distressing. Such distress, which may reduce the capacity for cooperation and considerateness, can be particularly troubling in times of crisis - such as the current pandemic - when partners' mutual care and emotional support are needed most.

Unlike gender differences in sexual interest, which have been extensively researched, both in evolutionary psychology (Buss, 1994) and sexology (see, for example, Mark et al., 2014), it is unclear if distress about sexual interest discrepancy may be gender-specific. Both genders report such distress (Pereira et al., 2019; Rosen et al., 2018), but the (gendered) direction of the mismatch has been shown to matter, at least in couples who recently became parents (Rosen et al., 2018).

\section{Current Study}

The current study aimed to further our understanding of changes in sexual interest ${ }^{2}$ for a steady partner and sexual distress about discrepant sexual interest during complex emergency situations-such as the current pandemic_-among individuals who were living with their partner or spouse at the time of the survey. Considering the importance of sexuality for relationship satisfaction and stability, as well as for

\footnotetext{
${ }^{2}$ In this study, we use the phrase sexual interest in place of the term sexual desire to express a more neutral (or deliberately ignorant) stance to biological underpinnings of human sexual motivation.
}

individual quality of life, an investigation into factors related to changes in sexual interest under complex emergency conditions has clinical and non-clinical ramifications. Our study diverged from the available literature by using used a well-powered multi-country sample of individuals who were cohabiting with their partner at the time of the survey and by addressing a role of approach vs. avoidance motives in retrospectively assessed changes of sexual interest and related distress. The following research questions were explored in the current study:

$R Q 1$ Has sexual interest for their partner changed among cohabiting individuals during the current pandemic, and is the pattern gender-specific?

$R Q 2$ To what extent are these, retrospectively assessed, changes reflected in distress about perceived discrepant sexual interest?

$R Q 3$ What are the sociodemographic predictors, and relational and situational correlates of COVID-19 related changes in sexual interest?

RQ4 What are the predictors and correlates of distress about discrepant sexual interest during the pandemic?

Based on the reviewed evidence about the relationship between the AAMM and sexual interest, we also tested the following hypothesis and a related research question:

H1 Based on some pre-pandemic evidence collected in student samples (Impett et al., 2005b, 2008), we expect that approach motivation for sex, compared to avoidance motives, would be associated with better maintenance of sexual interest and less distress about discrepant sexual interest during the pandemic.

\section{Method}

\section{Participants and Procedure}

A brief online survey (36 items in total), ${ }^{3}$ which was advertised as focusing on "possible impact of the pandemic on emotional intimacy and sexuality in long-term relationships and marriages", was carried out in seven EU countries (Croatia, the Czech Republic, France, Germany, the Netherlands, Portugal, and Sweden) and Turkey. Using national news websites and online social networks, a convenience sample of individuals aged $18-80$ was surveyed in each country. The

\footnotetext{
3 The questionnaire was intentionally very brief (based mostly on single-item indicators with high face validity) to avoid increasing pandemic-generated frustration and stress, as well as to minimize the number of participants leaving the survey before completing it (common in lengthy online questionnaires).
} 
target sample size of $\geq 500$ participants was reached only in the Czech Republic, the Netherlands, and Turkey (see Table 2). Only individuals aged $\geq 18$ years who were living with their partner/spouse at the time of the survey were eligible for the study. Data collection took place from May to July 2020 (Croatia: May 2-23; the Czech Republic: May 6-July 7; the Netherlands: May 9-30; Germany: May 13-June 20; Portugal: May 14-July 18; France: June 8-July 13; Sweden: June 12-July 13, Turkey: June 11-20).

The analytical sample included 4813 women and men who were living with a partner/spouse at the time of the survey ( $M_{\text {age }}=38.5$ years, $\mathrm{SD}=10.74 ; 73 \%$ of female participants). Of 6231 individuals who participated, 409 were excluded because they were either single or not living with their partner/spouse. Of those remaining, 1009 (17.3\%) answered less than half of all the questions (such response was the least prevalent in Germany and the Czech Republic, and the most prevalent in Turkey [23.4\%]). To address possible biases introduced by excluding these participants from the study, a multivariable logistic regression analysis was carried out with the following binary outcome: $0=$ completed less than $50 \%$ of the survey items and $1=$ completed $\geq 50 \%$ of the survey items. Independent variables were country dummies (reference $=$ the Netherlands), gender, age, years of (completed) formal education, and sexual orientation (living with a partner of the same or opposite sex). Being older $(\mathrm{AOR}=1.02, p<.001)$ and more educated $(\mathrm{AOR}=1.07$, $p<.001$ ) increased the odds, while reporting a heterosexual partnership/marriage (AOR $=0.58, p=.006$ ) decreased the odds of completing $\geq 50 \%$ of the survey items. Compared to Dutch participants, German (AOR $=0.60, p=.001)$ and Czech participants (AOR $=0.72, p=.033)$ were characterized by lower odds, and Croatian (AOR $=1.34, p=.029)$ and Turkish participants (AOR $=1.70, p<.001)$ by higher odds of responding to at least a half of questions.

Although their small number precluded meaningful statistical comparisons, 15 non-binary individuals $\left(M_{\mathrm{age}}=38.1\right.$, $\mathrm{SD}=15.40$ ) also participated in the survey (one in Croatia, two in the Czech Republic, five in Germany, two in Sweden, four in the Netherlands, and one in Turkey). All of them reported living with a partner; four with a man, eight with a woman, one with a non-binary partner, and two were in a polyamorous relationship. Four non-binary participants reported living with one or more children. On average, nonbinary individuals completed 16.2 years $(\mathrm{SD}=5.12)$ of formal schooling, which is slightly higher compared to female $(M=15.8, \mathrm{SD}=3.88)$ and male participants $(M=15.3$, $\mathrm{SD}=3.73)$.

Before accessing the online questionnaire, participants were asked to read general information about the study and prospective participation and register their electronic informed consent. Median time to complete the study was under nine minutes.

\section{Measures}

Sociodemographic indicators were age, gender, years of completed formal education, type of partnership/marriage (opposite-sex/same-sex), the number of years living together with the partner, and the number of kids in the household. We also asked about the ability to have some privacy during the pandemic ("Is there a room in the apartment/house where you live at the moment where you can be alone-if you need that—and do whatever you like?").

Change in the frequency of sexual activity was retrospectively assessed with the following sentence: "Compared to six months ago (i.e., before the pandemic), would you say that the frequency of sex (not only sexual intercourse but sexual activity in general) in your relationship/marriage has been: (1) much lower... (4) about the same... (7) much higher."

Change in sexual interest for one's partner was also measured retrospectively by a single-item measure: "Compared to six months ago (i.e., before the pandemic), would you say that your current interest in sex with your partner is: (1) much lower... (4) about the same... (7) much higher."

Distress about discrepant sexual interest during the pandemic was addressed using the following question: "How distressing do you find this current difference in sexual interest between you and your partner?" A 7-point scale ranging from $1=$ "not distressing at all" to $7=$ "extremely distressing" was used to record responses. Possible differences in sexual interest levels were addressed by asking participants if their "current interest in sex, compared to your partner's, is "much lower" (1) to "much higher" (7). Only individuals who reported a difference between their and their partner's levels of sexual interest at the time of the survey were asked about the related distress. Concurrent validity of the distress indicator was tested by carrying out a multivariable OLS regression with distress as dependent variable and change in sexual satisfaction ("Overall, would you say that your sexual satisfaction in your relationship/marriage is currently lower, higher or about the same compared to six months ago, that is before the pandemic?") as an independent variable. With country, age, and gender controlled for, retrospectively assessed change in sexual satisfaction was significantly associated with the outcome $(\beta=-0.29, p<.001)$. Increase in sexual satisfaction was expectedly related to lower distress during the pandemic.

Relationship satisfaction and emotional closeness before the pandemic was assessed by a latent combination of two constructs. The first was the 4-item Couples Satisfaction Index (Funk \& Rogge, 2007) that measures how much one feels happy and satisfied about their relationship and describes it as warm and rewarding using a 7-point scale to anchor answers (higher scores reflect higher relationship satisfaction). The scale had high internal consistency in the current study (Cronbach's $\alpha=0.94$ ). The second construct 
was perceived emotional closeness with a partner, which was a single-item measure showing seven Venn-like diagrams depicting a pair of circles with an increasing overlap representing partner's inclusion in the participant's self (Aron et al., 1992). The diagrams were preceded by the following question: "How close to or emotionally intimate with your partner/spouse did you feel before this pandemic?" The two constructs (five items in total) were analyzed using exploratory factor analysis with an oblique rotation. A single factor was extracted, with loadings in the 0.68-0.93 range. Higher factor scores indicate higher relationship satisfaction and emotional closeness.

Pandemic-related characteristics. Coping with the COVID-19 situation was measured by the following question: "How well do you cope with the current situation, that is with all life changes caused by this pandemic?". Answers were recorded on 7-point scale ranging from $1=$ "not well at all" to $7=$ "perfectly well." Partner's coping with the situation was assessed in a similar fashion: "In your opinion, how well does your partner cope with the current situation?". The same 7-point scale was used to anchor answers. Emotional well-being during the pandemic was indicated by answers to the following question: "In general, how are you doing, emotionally, these days?" ( $1=$ "completely negative", $7=$ "completely positive"). We also asked about mood changes ("Do you experience mood changes these days?"). Answers were anchored on a 7 -point scale $(1=$ never, $7=$ very often $)$. Worries about health were also measured by a single-item indicator ("How worried are you for your and your partner's health at the moment?", with answers recorded on a 7-point scale ( $1=$ "not at all", 7 = "extremely worried"). Finally, we asked about participants' perception of future ("How worried you are that this pandemic will negatively affect your future life in general?"). Again a 7-point scale, ranging from $1=$ "not at all" to $7=$ "a great deal", was used to record responses.

To create a latent composite, all six items were factor analyzed with an oblique rotation. After omitting the mood swings item, which cross-loaded highly on both factors, a two-factor solution was obtained, that explained $72 \%$ of item variance. The two factors - coping with the pandemic $(k=3)$ and worries about the pandemic $(k=2)$ were moderately correlated $(r=-.37)$. Internal consistency of both scales, which were entered in multivariable regression analyses as factor scores, were acceptable (Cronbach's $\alpha_{\text {coping }}=0.80$ and $\alpha_{\text {worries }}=0.60$ ). Higher scale scores indicate better coping with and more worries about the pandemic, respectively.

Motivation for sex. Following the conceptual approach by Gewirtz and Ayalon (2019), in which approach/avoidance motives were combined with personal/interpersonal goals to produce a $2 \times 2$ table of categories, the following four items were used to address types of personal motivation for sex: (A) "I want sex because it makes me feel good" (approach-personal motivation); (B) "I want sex because of what it does for my relationship" (approach-interpersonal motivation); (C) "I avoid sex because it does not make me feel good" (avoidancepersonal motivation); and (D) "I avoid sex because of what is going on in my relationship" (avoidance-interpersonal motivation). Participants were asked to select one of these "four possible motivations for sex in a committed relationship or marriage" - the one that "best represents how you felt before the pandemic". The categorical indicator's concurrent validity was supported by the finding that avoidance motivated participants (the personal/interpersonal goals distinction was disregarded in this analysis) were slightly more likely to report a significant reduction in sexual satisfaction during the pandemic than those characterized by approach motives $(t(503)=2.29, p<.023$; Cohen's $d=0.12)$.

Due to a small proportion of participants who reported personal and interpersonal avoidance motives $(4.6 \%$ and $5.4 \%$, respectively), the two categories were collapsed into one. In multivariable assessments, motives for sex were treated as two dummy variables, with personal approach motivation selected as reference category.

\section{Statistical Analyses}

Correlates and sociodemographic predictors of participants' perceived change in sexual interest during the pandemic were explored in a sequential multinomial logistic regression analysis. To distinguish between decrease, increase, and no change in sexual interest for a steady partner during the pandemic, the 7-point dependent variable was categorized into three groups: (A) participants who reported a decrease in sexual interest (values 1-3); (B) participants who reported no change (value 4); and (C) those who reported an increase in sexual interest (values 5-7). The largest of the three groups (i.e., participants who reported stable sexual interest) served as reference category. The model included the following independent variables: country dummies (the largest EU sample, the Netherlands, was chosen as reference), sociodemographic indicators, the relationship satisfaction and emotional closeness before the pandemic, types of motivation for sex (two dummy variables), also before the pandemic, and the two COVID-19 related latent measures (coping and worries).

Predictors and correlates of distress about perceived discrepancy in sexual interest during the pandemic were explored by an OLS regression analysis in which all independent variables from the previous analysis were included, together with the indicator of retrospectively assessed change in frequency of sexual activity due to the pandemic.

Missing values were rare on most key indicators $(<1 \%)$, except for COVID-19 related items ( $8 \%$ of missing values), change in the frequency of sex (6\%), and types of motivation for sex before the pandemic (7\% of missing values). The inclusion of all indicators in Little's MCAR test 
Table 1 Sociodemographic characteristics of the pooled sample $(N=4813)$

\begin{tabular}{|c|c|}
\hline & $n(\%)^{\mathrm{a}}$ \\
\hline \multicolumn{2}{|l|}{ Gender } \\
\hline Female & $3501(72.7 \%)$ \\
\hline Male & $1300(27.0 \%)$ \\
\hline Other & $12(0.2 \%)$ \\
\hline \multicolumn{2}{|l|}{ Number of children in the household } \\
\hline 0 & $2155(44.8 \%)$ \\
\hline 1 & $1061(22.0 \%)$ \\
\hline 2 & $1173(24.4 \%)$ \\
\hline 3 or more & $423(8.8 \%)$ \\
\hline \multicolumn{2}{|l|}{ Type of partnership } \\
\hline Heterosexual & $4553(96.9 \%)$ \\
\hline Homosexual & $146(3.1 \%)$ \\
\hline \multicolumn{2}{|c|}{ Being able to have some privacy in the household } \\
\hline Yes & $3166(71.6 \%)$ \\
\hline \multirow[t]{2}{*}{ No } & $1255(28.4 \%)$ \\
\hline & $M(\mathrm{SD})$ \\
\hline Age & $38.52(10.74)$ \\
\hline Years of completed formal education & $15.85(3.66)$ \\
\hline Years of living together & $10.56(9.52)$ \\
\hline
\end{tabular}

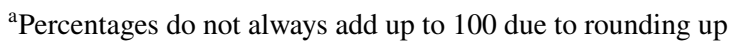

$\left(\chi^{2}(318)=460.60, p<.001\right)$ suggested that data were not missing completely at random. All statistical procedures were carried out using IBM SPSS 27 statistical software package.

\section{Results}

Sample characteristics are shown in Table 1. More than two thirds of all participants were women $(72.7 \%)$. The proportion of men varied from $7.6 \%$ in Turkey to $49 \%$ in the Netherlands. Women were somewhat younger $(M=36.7$, $\mathrm{SD}=9.4)$ than men $(M=43.6, \mathrm{SD}=12.4)$. Due to their small number $(n=12)$, participants who gender identified as other, were excluded from further analyses. About a half of the sample reported living with one or more children $(55.2 \%)$. Mean number of years of completed formal schooling was 15 (some college education), ranging from 13.5 in German to 16.9 years among Portuguese participants. Only $3.1 \%$ of surveyed individuals reported living with a partner/spouse of the same sex $(1.4 \%$ in Turkey and $4.5 \%$ in the Netherlands). On average, participants in the current study had been living together with their partner for more than a decade (10.6 years).

Slightly over a half of participants reported no change in their retrospectively assessed sexual interest during the COVID-19 pandemic (52.8\%). Of the rest, $18.8 \%$ reported a decrease, while $28.5 \%$ reported an increase in their sexual interest. We observed a slight but statistically significant gender difference in mean changes: $t(4794)=3.04$, $p=.002$; Cohen's $d=0.10$ ), with a cross-tabulation analysis indicating that, compared to men, women more often reported a decrease and less often stability in sexual interest for their partner. No gender difference was observed among participants who reported an increased interest. When the pattern of change was compared across the eight countries, a single significant difference emerged, with Dutch participants reporting a slightly different pattern (characterized by a higher frequency of increased sexual interest) than the rest $(F(7,4807)=7.00, p<.001)$. Table 2 presents detailed information about mean changes in sexual interest by country and gender.

The pandemic-related changes in sexual interest were weakly associated with distress about perceived discrepancy $\left(r_{\mathrm{S}}=-0.21, p<.001\right)$, with the link somewhat stronger among female $\left(r_{\mathrm{S}}=-0.25, p<0.001\right)$, compared to male participants $\left(r_{\mathrm{S}}=-0.14, p<.001\right)$. The relationship was significant among heterosexual $\left(r_{\mathrm{S}}=-0.22, p<.001\right)$ but not non-heterosexual participants ( $r h o=-0.06, p=.597$ ). Considering that changes in sexual interest were not necessarily accompanied with distress, we next explored levels of distress about perceived discrepant sexual interest. One fifth of individuals who reported any change in their sexual interest during the pandemic reported no distress (20.9\%), 29.1\% reported low distress levels (values 2-3), 
Table 2 Descriptive information about changes in personal sexual interest during the pandemic by country and gender

\begin{tabular}{llllllrrr}
\hline & $\mathrm{HR}(n=491)$ & $\mathrm{CZ}(n=534)$ & $\mathrm{NL}(n=925)$ & $\mathrm{DE}(n=526)$ & $\mathrm{FR}(n=357)$ & \multicolumn{1}{l}{$\mathrm{PT}(n=474)$} & $\mathrm{SE}(n=353)$ & \multicolumn{1}{l}{$\mathrm{TR}(n=1137)$} \\
& $M(\mathrm{SD})$ & $M(\mathrm{SD})$ & $M(\mathrm{SD})$ & $M(\mathrm{SD})$ & $M(\mathrm{SD})$ & $M(\mathrm{SD})$ & \multicolumn{1}{l}{$M(\mathrm{SD})$} & $M(\mathrm{SD})$ \\
\hline Women & $4.1(1.3)$ & $4.1(1.1)$ & $4.2(1.3)$ & $4.1(1.2)$ & $3.9(1.3)$ & $4.1(1.3)$ & $4.2(1.1)$ & $4(1.5)$ \\
Men & $4.2(1.4)$ & $4(1.2)$ & $4.5(1.1)$ & $4(1.1)$ & $4.2(1.1)$ & $4(1.3)$ & $4(1)$ & $4.2(1.7)$ \\
Total & $4.2(1.4)$ & $4.1(1.1)$ & $4.4(1.2)$ & $4.1(1.2)$ & $4(1.3)$ & $4.1(1.3)$ & $4.1(1)$ & $4(1.5)$ \\
\hline
\end{tabular}

Changes in personal sexual interest ranged from $1=$ much lower than before the pandemic to $7=$ much higher than before the pandemic. $\mathrm{HR}=$ Croatia $\mathrm{CZ}=$ the Czech Republic $($ Czechia) $\mathrm{NL}=$ the Netherlands; $\mathrm{DE}=$ Germany; $\mathrm{FR}=$ France $\mathrm{PT}=$ Portugal; $\mathrm{SE}=\mathrm{Sweden} ; \mathrm{TR}=\mathrm{Tur}-$ key

$31.0 \%$ moderate distress levels (values $4-5$ ), and $18.9 \%$ high levels of distress about sexual interest discrepancy in their relationship/marriage. Mean distress levels were somewhat higher $(t(2707)=4.04, p<.001$, Cohen $d=0.17)$ among male $(M=3.8, \mathrm{SD}=2.0)$ than female participants $(M=3.5$, $\mathrm{SD}=2.0)$.

Finally, the pattern of sexual motives prior to the pandemic was similar across gender and countries (Table 3). Most participants reported desiring sex for personal reasons (61.6\%), followed by wanting it for what it means for their relationship (28.4\%). Avoidance motives were rare (10\%). There were significant gender differences in two of the three motivation types. More women than men reported avoidance motives $\left(\chi^{2}(1, N=4482)=24.60, p<.001\right)$. Female to male ratio in the avoidance category was almost $2: 1$. Avoidance motives were the highest among Turkish (14.1\%) and the lowest in Swedish women $(6.8 \%)$. Compared to men, significantly fewer women reported ego-focused approach motivation for $\operatorname{sex}\left(\chi^{2}(1, N=4482)=5.87, p=.016\right)$.

\section{Multivariate Assessment}

Findings from a multinomial logistic regression analysis of retrospectively reported changes in sexual interest during the pandemic are presented in Table 4. Controlling for countryspecific differences in the dynamics and national response to the COVID-19 pandemic, the odds of reporting reduced levels of sexual interest, compared to no change, were increased by female gender ( $\mathrm{AOR}=1.33, p=.012$ ), years of education (AOR $=1.03, p=.029$ ), and worries about COVID-19 (AOR $=1.15, p=.004)$. Relationship satisfaction and emotional closeness $(\mathrm{AOR}=0.76, p=.029)$, and better coping with the pandemic situation $(\mathrm{AOR}=0.55, p<.001)$ reduced the odds of decreased sexual interest.

The odds of reporting an increase in sexual interest, relative to reporting a stable interest, were substantially increased by relationship satisfaction and emotional closeness $(\mathrm{AOR}=1.25, p<.001)$, and both coping $(\mathrm{AOR}=1.14$, $p=.004)$ and worries (AOR $=1.09, p=.043)$ about the pandemic, but decreased by age $(\mathrm{AOR}=0.97, p<.001)$. In addition, the odds of increased interest were significantly reduced by reporting both avoidance $(\mathrm{AOR}=0.69, p=.013)$ and relationship-focused approach motivation for sex $(\mathrm{AOR}=0.80$, $p=.007)$-compared to ego-focused approach motives. While the odds of reporting decreased sexual interest seemed uniform across countries, reports of increased interest were significantly less prevalent in other EU countries (but not Turkey) compared to the Netherlands.

The second regression analysis (Table 5) explored sociodemographic predictors and other correlates of distress about discrepant sexual interest. Controlling for country-specific differences, sexual distress levels were negatively associated with female gender $(\beta=-0.10, p<.001)$, participant's age $(\beta=-0.10, p=.001)$, having some privacy in the household

Table 3 Sexual motivation types prior to the COVID-19 pandemic by country and gender

\begin{tabular}{llrrrr}
\hline Country & Gender & \multicolumn{5}{l}{ Sexual motivation type } & & \\
\cline { 3 - 6 } & & $A n(\%)$ & $B n(\%)$ & $C n(\%)$ & $D n(\%)$ \\
\hline Croatia & Women & $164(57.3)$ & $88(30.8)$ & $6(2.1)$ & $28(9.8)$ \\
& Men & $88(56.1)$ & $56(35.7)$ & $4(2.5)$ & $9(5.7)$ \\
Czechia & Women & $237(58.8)$ & $130(32.3)$ & $22(5.5)$ & $14(3.5)$ \\
& Men & $68(65.4)$ & $30(28.8)$ & $2(1.9)$ & $4(3.8)$ \\
France & Women & $140(51.1)$ & $98(35.8)$ & $11(4.0)$ & $25(9.1)$ \\
& Men & $29(49.2)$ & $25(42.4)$ & $2(3.4)$ & $3(5.1)$ \\
Germany & Women & $176(55.5)$ & $110(34.7)$ & $18(5.7)$ & $13(4.1)$ \\
& Men & $132(69.8)$ & $47(24.9)$ & $9(4.8)$ & $1(0.5)$ \\
Nether- & Women & $270(59.5)$ & $138(30.4)$ & $31(6.8)$ & $15(3.3)$ \\
lands & Men & $277(64.9)$ & $125(29.3)$ & $16(3.7)$ & $9(2.1)$ \\
Portugal & Women & $199(65.9)$ & $69(22.8)$ & $18(6.0)$ & $16(5.3)$ \\
& Men & $97(66.4)$ & $42(28.8)$ & $3(2.1)$ & $4(2.7)$ \\
Sweden & Women & $174(62.1)$ & $87(31.1)$ & $8(2.9)$ & $11(3.9)$ \\
& Men & $38(67.9)$ & $14(25)$ & $1(1.8)$ & $3(5.4)$ \\
Turkey & Women & $618(64.8)$ & $200(21)$ & $50(5.2)$ & $85(8.9)$ \\
& Men & $53(70.7)$ & $15(20)$ & $6(8.0)$ & $1(1.3)$ \\
Total & Women & $1978(60.5)$ & $920(28.1)$ & $164(5.0)$ & $207(6.3)$ \\
& Men & $782(64.5)$ & $354(29.2)$ & $43(3.5)$ & $34(2.8)$ \\
\hline
\end{tabular}

$\mathrm{A}=$ Ego-focused approach motivation; $\mathrm{B}=$ Relationship-focused approach motivation; $\mathrm{C}=$ Ego-focused avoidance motivation; $\mathrm{D}=$ Relationship-focused avoidance motivation 
Table 4 Predictors and correlates of changes in sexual interest during COVID19 pandemic (Reference Group $=$ No Change)

\begin{tabular}{|c|c|c|c|c|}
\hline & \multicolumn{2}{|c|}{ Decreased sexual interest } & \multicolumn{2}{|c|}{ Increased sexual interest } \\
\hline & AOR & $95 \% \mathrm{CI}$ & AOR & $95 \% \mathrm{CI}$ \\
\hline Female gender & $1.33 *$ & $0.59-94$ & 1.02 & $0.85-1.22$ \\
\hline Age & 0.99 & $0.98-1.01$ & $0.97 * * *$ & $0.96-0.98$ \\
\hline Years of (completed) formal education & $1.03 *$ & $1.01-1.06$ & 0.99 & $0.96-1.01$ \\
\hline Living together (in years) & 0.99 & $0.97-1.01$ & 1.00 & $0.99-1.01$ \\
\hline Number of children in the household & 0.94 & $0.86-1.03$ & 1.00 & $0.93-1.08$ \\
\hline Having privacy in the household & 1.11 & $0.92-1.35$ & 0.92 & $0.77-1.08$ \\
\hline Relationship satisfaction and closeness & $0.76 * * *$ & $0.69-0.84$ & $1.25 * * *$ & $1.13-1.38$ \\
\hline \multicolumn{5}{|l|}{ Motivation for $\operatorname{sex}^{\mathrm{a}}($ reference $=\mathrm{A})$} \\
\hline B & 1.04 & $0.85-1.27$ & $0.80 * *$ & $0.68-0.94$ \\
\hline $\mathrm{C} / \mathrm{D}$ & 0.76 & $0.57-1.02$ & $0.69 *$ & $0.51-0.92$ \\
\hline Coping with COVID-19 situation & $0.55 * * *$ & $0.49-0.60$ & $1.14 * *$ & $1.04-1.25$ \\
\hline Worries about COVID-19 situation & $1.15^{* *}$ & $1.05-1.27$ & $1.09 *$ & $1.01-1.18$ \\
\hline \multicolumn{5}{|l|}{ Country (reference $=$ the Netherlands) } \\
\hline Croatia & 1.13 & $0.78-1.63$ & $.58 * * *$ & $1.41-2.48$ \\
\hline Czechia & 0.92 & $0.65-1.30$ & $.61 * * *$ & $1.29-2.20$ \\
\hline France & 0.68 & $0.47-1.01$ & $.64 * *$ & $1.15-2.19$ \\
\hline Germany & $0.63 *$ & $0.45-0.90$ & $.71 *$ & $1.09-1.88$ \\
\hline Portugal & 1.13 & $0.78-1.62$ & $.75^{*}$ & $1.06-1.88$ \\
\hline Sweden & 1.10 & $0.73-1.67$ & $.50 * * *$ & $1.46-2.78$ \\
\hline Turkey & 0.90 & $0.66-1.22$ & .84 & $0.97-1.55$ \\
\hline Observations $=4359$ & & & & \\
\hline
\end{tabular}

$* p<.05 . \quad * * p<.01 . * * * p<.001$

${ }^{a}$ Before the pandemic; $\mathrm{A}=$ Ego-focused approach motivation; $\mathrm{B}=$ Relationship-focused approach motivation; $\mathrm{C} / \mathrm{D}=$ avoidance motivation; $\mathrm{CI}=$ confidence interval around adjusted odds ratio $(A O R)$ $(\beta=-0.07, p<.001)$, better coping with the emergency situation $(\beta=-0.05, p=.020)$, and reported change in the frequency of sexual activity during the pandemic $(\beta=-0.16$, $p<.001)$. The strongest effect size was observed for the association between higher relationship satisfaction and closeness and lower distress $(\beta=-0.26, p<.001)$. Distress about discrepant sexual interest was substantially higher in individuals who expressed more COVID-19 related worries $(\beta=0.13$, $p<.001)$ and participants characterized by the relationshipfocused approach motives for $\operatorname{sex}(\beta=0.10, p<.001)$ - when contrasted to ego-focused approach motivated individuals.

\section{Robustness Analysis}

To check the robustness of the findings, the multinomial regression analysis was re-estimated using all cases by applying multiple imputation (MI). Following more recent recommendations, 20 datasets were used for MI (Baraldi \& Enders, 2010; Graham, 2012). When the results were compared to those obtained with listwise omission of cases with missing values, the pattern of (non)significant findings (see Table 4) remained unchanged. Thus, sensitivity analysis for the second regression analysis (with distress about discrepant sexual interest as outcome) did not include MI, but bootstrapping using 5000 resamples. The procedure seemed warranted considering a substantially skewed distribution of the dependent variable. Bootstrapping resulted in the identical pattern of (non)significant findings as presented in Table 5.

\section{Discussion}

The current study aimed to contribute to insights about the dynamics of sexual interest in the current complex emergency caused by the COVID-19 pandemic. Before delving into contextualizing and discussing the current study findings in more detail, we start with summary answers to the four research questions:

Has sexual interest changed during the current pandemic and is the pattern gender-specific? Slightly over a half of the surveyed participants reported no perceived change in sexual interest for their partner during the pandemic; of the rest, there were more individuals who reported increased than decreased interest. This pattern of stability/change was gender-specific, with more female participants reporting a decrease and less reporting no change in their sexual interest compared to their male counterparts. 
Table 5 Predictors and correlates of distress about discrepancy in partners' sexual interest during the pandemic

\begin{tabular}{lll}
\hline & $B(\mathrm{SE})$ & $\beta$ \\
\hline Female gender & $-.43(.09)$ & $-.10^{* * *}$ \\
Age & $-.02(.01)$ & $-.10^{* *}$ \\
Years of formal education & $-.01(.01)$ & -.01 \\
Cohabitation duration (in years) & $.01(.01)$ & .01 \\
Number of children in the household & $-.01(.04)$ & -.01 \\
Having privacy in the household & $-.31(.08)$ & $-.07^{* * *}$ \\
Relationship satisfaction and emotional & $-.51(.05)$ & $-.26^{* * *}$ \\
$\quad$ closeness & & \\
Motivation for sex ${ }^{\mathrm{a}}$ (reference=A) & & \\
B & $.44(.08)$ & $.10^{* * *}$ \\
C/D & $-.07(.12)$ & -.01 \\
Change in frequency of sexual activity & $-.22(.03)$ & $-.16^{* * * *}$ \\
Coping with COVID-19 situation & $-.10(.04)$ & $-.05^{*}$ \\
Worries about COVID-19 situation & $.25(.04)$ & $.13^{* * *}$ \\
Country (reference=the Netherlands) & & \\
Croatia & $-.94(.15)$ & $-.14^{* * * *}$ \\
Czechia & $-.10(.14)$ & -.02 \\
France & $-.86(.16)$ & $-.11^{* * * *}$ \\
Germany & $-.44(.13)$ & $-.07^{* * *}$ \\
Portugal & $-.17(.14)$ & -.03 \\
Sweden & $-.14(.17)$ & -.02 \\
Turkey & $-.47(.12)$ & $-.10^{* * * *}$ \\
Observations & 2475 & \\
Adjusted $R^{2}$ & .18 & \\
\hline & & \\
\hline
\end{tabular}

${ }^{*} p<.05 . * * p<.01 . * * * p<.001$

${ }^{a}$ Before the pandemic; $\mathrm{A}=$ Ego-focused approach motivation; $\mathrm{B}=$ Relationship-focused approach motivation; $\mathrm{C} / \mathrm{D}=$ Avoidance motivation

${ }^{\mathrm{b}}$ During the pandemic

To what extent are changes in partnered individuals' sexual interest reflected in distress about discrepant sexual interest? Retrospectively reported changes were only weakly associated with distress about perceived sexual interest discrepancy (the correlation was higher in female than male participants). A majority of surveyed individuals reported no or low distress, but $19 \%$ of participants were highly distressed (the categorization, it should be noted, was not based on clinically validated cutoff scores).

Which personal and situational characteristics are related to changes in sexual interest? Which characteristics are related to distress about discrepant sexual interest? Changes in sexual interest during the COVID-19 pandemic were consistently associated with two factors: relationship satisfaction and emotional closesness, and coping with the complex emergency situation. Similarly, levels of distress about discrepant sexual interest were best predicted by relationship satisfaction and partner's emotional closeness, and participants' worries about the pandemic.

Finally, we expected that approach motivation for sex, compared to avoidance motives, would be associated with better maintenance of sexual interest and less distress about discrepant sexual interest. Interestingly, we observed no differences in retrospectively assessed reduction in sexual interest across the four sexual motivation types. In contrast, compared to other types, ego-oriented motives were substantially associated with increase in sexual interest during the pandemic. Pointing to the importance of distinguishing between personal and interpersonal sexual motivation, relationship-oriented approach motivation was significantly related to distress about perceived discrepancy in sexual interest. The observation that individuals who reported that interpersonal benefits were their primary motives for sex before the pandemic were more distressed by the discrepancy than ego-oriented participants should not be surprising. The former motivation is markedly more vulnerable to complex emergencies than the latter motives for one simple reason-with pandemic-related pressures increasing, the burden placed on sex to take care of the relationship intensifies. In the process, distress about a mismatch in sexual interest becomes more likely, as the discrepancy is perceived not only as an obstacle to sexual pleasure, but also as an obstacle to attending to partners' emotional bond.

Our finding that almost a half of surveyed women and men reported no change in their sexual interest-which was the pattern observed across the eight countries - is at odds with most other studies, which noted a substantial decrease in sexual activity, sexual desire, and/or quality of their sex life (Jacob et al., 2020; Lehmiller et al., 2021; W. Li et al., 2020; Schiavi et al., 2020). Only a small Turkish study (Yuksel \& Ozgor, 2020) reported findings comparable to ours. Recognizing that differences may be related to the fact that some of these studies collected data during earlier phases of the pandemic - possibly fraught with more intense health-related concerns and fears - the differences most likely reflect the fact that the earlier studies mostly surveyed single individuals and, in the case of the two Chinese studies, people living with their parents (G. Li et al., 2020, W. Li et al., 2020). Comparisons among the studies is further hampered by differences in participants age and their relationship status, the use of different measures, as well as by country-specific dynamics of the pandemic and the public health response regimes.

There were two notable gender differences in our study. The first was the gender-specific pattern of change in sexual interest, with partnered male participants reporting more stability and less decrease in sexual interest than female participants. The finding, which is compatible with the findings from a longitudinal study of sexual desire in a Canadian sample (Brotto et al., 2021), may reflect women's higher parenting and household investments is some countries, particularly 
during lockdowns and at home TV-based schooling, higher levels of health-related concerns (women are generally more involved in health matters; Hunt et al., 2010), different coping strategies, or other characteristics. The second gender-related difference was higher distress about discrepant sexual interest observed among male participants. This may be related to the finding that more women than men reported a decrease in sexual interest during the pandemic. Thus, higher distress might reflect a combination of negative feelings and uneasiness about what could have been perceived as partner's sexual withdrawal in times of crisis. Finally, we observed some gender differences in types of motivation for sex, which were shown to be associated with sexual well-being during the pandemic. In all eight countries, women were more likely to report avoidant sexual motivation than men. However, the proportion of avoidant motivated female participants varied across country, suggesting a role of socio-cultural factors. Considering that ego-focused approach motives for sex were associated with increase in sexual interest for one's partner and were associated with lower levels of sexual distress when compared to other motivation types, it should also be noted that more men than women were characterized by ego-focused approach motivation before the pandemic. The difference should not be hastily ascribed to gender-specific sexual socialization and gendered social norms intended to regulate sexuality, because we found no gender differences in relationship-focused approach motives for sex.

Retrospectivelly reported changes (i.e., decrease or increase) in personal sexual interest for the cohabiting partner during the pandemic were associated with all four groups of indicators: sociodemographic, relational, situational, or pandemic-related, and personal motivation for sex. Among sociodemographic characteristics, male gender increased the odds of reporting increased sexual interest, while age and education worked in the opposite direction. The link with education is interesting and may suggest that, during lockdown, white collar professions continued working online, sometimes with even more pressure and blurred lines between working and non-working hours. Higher relationship satisfaction and emotional closeness scores increased the odds of increased sexual interest, while lower scores increased the odds of reporting a decline in sexual interest during the pandemic. Taken together, the findings underscore the importance of relationship quality for sexual health and well-being (Hinchliff \& Gott, 2004; Schoenfeld et al., 2017; Štulhofer et al., 2013, 2020).

Situational, COVID-19-related, factors were also important. Better coping with the situation was linked to increased and worse coping to decreased sexual interest. Surprisingly, worries about the pandemic significantly (and with similar effect size) increased the odds of reporting both increased and decreased sexual interest. It appears that fear and concerns caused by the pandemic suppress sexual interest in some but boost it for other participants. In the latter case, sex may serve as a distractor or a sexualized coping strategy, which resonates with observations that a proportion of individuals characterized by negative mood report increased, rather than decreased sexual desire (Bancroft et al., 2003; Janssen et al., 2013; Lykins et al., 2006).

Finally, ego-focused approach motivation for sex was significantly related to increased sexual interest in one's partner, but also to lower stress about perceived discrepant sexual interest compared to relationship-focused approach motives. The findings are surprising only if one believes that the pandemic increased pressure to have sex primarily to support the partner and the relationship — which does not seem to be the case. If, however, the life-course framework proves essential for the AAMM, demonstrating that relationship-focused approach motives become more prominent and beneficial for sustaining a couple's sexual interest with aging (GewirtzMeydan \& Ayalon, 2019; Hinchliff \& Gott, 2004), our findings might be limited by the average age of participants in our sample.

Among other predictors and correlates of distress about partners' discrepant sexual interest during the pandemic, female gender, younger age, lack of privacy, and more worries about the COVID-19 situation were associated with higher distress levels. Higher frequency of sexual activity, higher levels of relationship satisfaction and emotional closeness, and self-reported better coping with the pandemic were related to lower distress levels. Comparable to the analysis of changes in sexual interest, the relational dimension (indicated by the relationship satisfaction and emotional closeness latent construct) and participant's reaction to the crisis most contributed to the explained variance in sexual discrepancyrelated distress. The fact that our model accounted for less than a fifth of variance in the outcome points to the existence of other, unmeasured, factors, possibly professional stress, wider emotional support networks, etc.

Although cultural differences were not the main focus of this multi-country study, it should be noted that the reported pattern of retrospectively assessed change in sexual interest exhibited no difference across seven of the eight countries included-despite notable differences in the severity of the pandemic and governmental responses to it at the time of our survey (Brauner et al., 2021). We also observed some between-country differences, most notable in levels of distress about discrepant sexual interest and gender-specific motivation for sex. How much these differences reflect more durable socio-cultural differences, relative to the impact of COVID 19, remains unclear, but comparative social science research points to a substantial diversity of attitudes toward gender equality and sexual permissiveness in Europe (see, for example, Luijkx et al., 2016).

We were unable to explore possible links between retrospectively assessed changes in sexual interest and levels 
of distress as psychological reactions to the pandemic on the one hand and country-specific COVID-19 societal costs and psychosocial burdens on the other hand. The reasons are methodological (non-probability sampling, different timing of online recruitment in the eight countries, and a small number of countries included), bio-political (i.e., different dynamics of the pandemic and differences in country response), and socio-epidemiological (differences in national testing strategy, laboratory capacity, surveillance approach, public reporting of new cases, and the definition of COVID-19 related death). All this prompted the European Centre for Disease Prevention and Control to state that notification rates should not be used to "directly compare countries" (ECDC, 2020). Another possible approach to cross-country comparisons would be to focus on stringency levels of country-specific pandemic measures, which has recently been enabled by the Oxford University COVID-19 Government Response Tracker (OxCGRT; Hale et al., 2021). According to the OxCGRT, the stringency levels on June 1 varied considerably in the eight countries included in the current study, ranging from 41.7 in the Czech Republic to 71.3 in Portugal. ${ }^{4}$ Although it would be tempting to explore possible links between government restrictions and sexualityrelated outcomes at individual level, such analysis would be unwarranted given the small number of countries in the current study. Furthermore, national responses to the pandemic were sometimes region-specific and changing in stringency during the time of our data collection.

\section{Clinical Relevance}

The finding that only a few predictors/correlates of distress were static and unchangeable (such as age and gender) means that other, more dynamic and malleable, factors could potentially be influenced. So, the question arises as to the consequences of our results for possible counselling or clinical interventions. For couples who might be together $24 \mathrm{~h}$ a day due to a lockdown, possibly with children, and without sufficient privacy at home, the quality of relationship becomes essential. Considering that even satisfying relationships can be vulnerable to a combination of economic, psychological, and medical burdens of a complex emergency situation, it is important to think about possibilities of professional support and interventions. These could follow the recent recommendations of the European Society for Sexual Medicine (Dewitte et al., 2020) to assist couples who are distressed by sexual desire discrepancy by depathologizing variations

\footnotetext{
${ }^{4}$ On June 1, the OxCGRT stringency levels were 63.9 in Turkey, 50.9 in Croatia, 71.7 in the Czech Republic, 75.0 in France, 59.7 in Germany, 63.0 in the Netherlands, 71.3 in Portugal, and 64.8 in Sweden (see https://covidtracker.bsg.ox.ac.uk/stringency-scatter).
}

in sexual desire-without neglecting the possibility that some couples will need a more complex intervention (i.e., sex therapy). In relation to the COVID-19 situation, promoting dyadic sexual communication about personal concerns, coping strategies, as well as sexual needs and motives, is of central importance. In the situation of restricted social contacts and limited access to health services, the use of e-health information, counselling, and/or sex therapy platforms could be an option (Kirana et al., 2020).

\section{Strengths and Limitations}

The current study used a well-powered multi-country sample, recruited via an online survey that used a very brief questionnaire. This resulted in a high completion rate, despite many COVID-19 related surveys circulating online at the same time. Probably the main limitation of our study, non-probability (i.e., convenience) sampling, precluded any generalizations, as well as any emphasis on direct comparisons between the eight countries. However, this shortcoming is of limited importance here because our main aim was not descriptive or prevalence-focused, but analytical. Compared to the former, the latter aim mostly requires a sample that is large enough (power issues) and heterogeneous (sufficient variability in characteristics of interest). Although women and highly educated individuals are markedly overrepresented in our sample ${ }^{5}$ - which is often the case with sexuality-related, particularly internet-based, studies (see, for example, Ross et al., 2005) — we believe that the sociodemographic characteristics presented in Table 1 point to an acceptable diversity of partnered individuals. Another notable limitation is the fact that changes in sexual interest were assessed retrospectively. Compared to prospective (i.e., longitudinal) assessments, retrospective explorations are less valid and robust, mostly due to recall bias and the inability to address nestedness of the data in time.

A different type of limitation is our approach to measuring approach/avoidance motivation for sex. Although the operationalization was firmly anchored in the literature (Elliot et al., 2006; Gable \& Impett, 2012; Gable \& Poore, 2008; Gewirtz-Meydan \& Ayalon, 2019), which suggests that the two motivations are relatively independent (and not the end points on a continuum), our use of single-item measures-justified by the intentional brevity of our questionnaire- to assess complex constructs is certainly not an ideal choice. In the future, the four motivation types should be treated as latent constructs (i.e., indicated by multiple items),

\footnotetext{
5 Similar overrepresentation of female participants (71\% of the total sample) was reported in another recent large-scale online survey that focused on sexuality in times of the COVID-19 pandemic (Lehmiller et al., 2021). The study, in which a large majority of participants were from North America, was carried out a couple of months before ours.
} 
as such strategy should bring more precision and allow for testing some of the conceptual assumptions. To the best of our knowledge, no validated measure of the four motivation of sex types is currently available. This remains a task for future studies.

\section{Conclusion}

Several findings from this cross-cultural study that sampled partnered individuals from the North, South, East, and West of Europe should be emphasized and checked against results from comparable studies (see Döring, 2020). The first is the observation that the majority of individuals who lived with a partner or spouse at the time of the survey did not seem to have reacted to the pandemic with reduced sexual interest for their partner. In fact, almost a third retrospectively reported an increase in sexual interest, which may have been beneficial to their personal and relationship well-being, as well as for coping with the crisis generated by the pandemic. Second, changes in sexual interest were weakly associated with perceived distress about discrepant sexual interest, and only a minority of participants appeared highly distressed. Third, relationship satisfaction and emotional closeness were confirmed to be highly important couple resources in times of crisis. The novel insight in this respect is the current study finding that the effect (not meant here to denote causality) does not require that a couple's sex is primarily motivated by its benefits for the relationship. Under complex emergency circumstances, partnered women's and men's approach motives for sex seem to contribute to sexual well-being the most when they are ego-oriented (i.e., focused on personal pleasure and enjoyment). By shedding some light on factors that decrease/increase the risk of couple distress about discrepant sexual interest during the COVID-19 pandemic, the current study findings may facilitate clinical work with partnered individuals and couples whose sex life is affected by the pandemic - particularly in terms of supporting adaptive coping and paying attention to possible gender-specific sexual reactions.

Finally, two important caveats are required. The current study findings are clearly limited to European experiences with the COVID-19 pandemic in the period from May to July 2020. Considering that the complex emergency situation continues without an end in sight, the experiences, behaviors, and perceptions explored in this study are prone to change.

Funding The study was carried out under the auspices of the COST 2019-2023 Action European Sexual Medicine Network (CA18124; https://www.esmn-cost.eu/), but no direct funding was obtained for the study.

\section{Declarations}

Conflict of interest The authors have no potential conflict of interest to disclose.

Human and Animal Rights All applicable international, national, and/ or institutional guidelines for ethical research with human participants were closely followed. All study procedures were approved by Institutional Review Boards in Croatia (the Department of Sociology, Faculty of Humanities and Social Sciences, University of Zagreb), Germany (Local Psychological Ethical Review Board of the Center for Psychosocial Medicine at the University Medical Center Hamburg-Eppendorf, Hamburg, Germany; LPEK-0150), Sweden (Swedish Ethical Review Authority; record no: 2020-02,708), France (Comité éthique AMU / Aix-Marseilles University Ethics Committee; N/Réf: 2019-09-07-003), the Czech Republic (Ethical Review Board of the National Institute of Mental Health, Klecany, Czech Republic; approval number: 115/20), and Portugal (Comissão de Ética do ISPA-Instituto Universitário).

Informed Consent Informed consent was obtained from all individual participants included in the study.

\section{References}

Albala-Bertrand, J. M. (2000). Responses to complex humanitarian emergencies and natural disasters: An analytical comparison. Third World Quarterly, 21(2), 215-227. https://doi.org/10.1080/01436 590050004328

Aron, A., Aron, E. N., \& Smollan, D. (1992). Inclusion of Other in the Self Scale and the structure of interpersonal closeness. Journal of Personality and Social Psychology, 63(4), 596-612. https://doi. org/10.1037/0022-3514.63.4.596

Aversa, A., \& Jannini, E. A. (2020). COVID-19, or the triumph of monogamy? Minerva Endocrinologica, 45, 77-78. https://doi. org/10.23736/S0391-1977.20.03207-1

Bancroft, J., Janssen, E., Strong, D., Carnes, L., Vukadinovic, Z., \& Long, J. S. (2003). The relation between mood and sexuality in heterosexual men. Archives of Sexual Behavior, 32(3), 217-230.

Baraldi, A. N., \& Enders, C. K. (2010). An introduction to modern missing data analyses. Journal of School Psychology, 48(1), 5-37. https://doi.org/10.1016/j.jsp.2009.10.001

Bedford, J., Enria, D., Giesecke, J., Heymann, D. L., Ihekweazu, C., Kobinger, G., Lane, H. C., Memish, Z., Oh, M.-D., Sall, A. A., Schuchat, A., Ungchusak, K., \& Wieler, L. H. (2020). COVID19: Towards controlling of a pandemic. The Lancet, 395(10229), 1015-1018. https://doi.org/10.1016/S0140-6736(20)30673-5

Bendau, A., Petzold, M. B., Pyrkosch, L., MascarellMaricic, L., Betzler, F., Rogoll, J., Große, J., Ströhle, A., \& Plag, J. (2020). Associations between COVID-19 related media consumption and symptoms of anxiety, depression and COVID-19 related fear in the general population in Germany. European Archives of Psychiatry and Clinical Neuroscience, 1, 3. https://doi.org/10.1007/s00406-020-01171-6

Brauner, J. M., Mindermann, S., Sharma, M., Johnston, D., Salvatier, J., Gavenčiak, T., Stephenson, A. B., Leech, G., Altman, G., Mikulik, V., Norman, A. J., Monrad, J. T., Besiroglu, T., Ge, H., Hartwick, M. A., Teh, Y. W., Chindelevitch, L., Gal, Y., \& Kulveit, J. (2021). Inferring the effectiveness of government interventions against COVID-19. Science, 371. https://doi.org/10.1126/science.abd9338

Brezsnyak, M., \& Whisman, M. A. (2004). Sexual desire and relationship functioning: The effects of marital satisfaction and power. Journal of Sex and Marital Therapy, 30(3), 199-217. https://doi. org/10.1080/00926230490262393 
Brotto, L. A., Jabs, F., Brown, N., Milani, S., \& Zdaniuk, B. (2021). Impact of COVID-19 related stress on sexual desire and behavior in a Canadian sample. International Journal of Sexual Health. https://doi.org/10.1080/19317611.2021.1947932

Buss, D. M. (1994). The evolution of desire: Strategies of human mating. Basic Books.

Cacioppo, J. T., \& Berntson, G. G. (1999). The affect system: Architecture and operating characteristics. Current Directions in Psychological Science, 8(5), 133-137. https://doi.org/10.1111/14678721.00031

Carvalheira, A., Traeen, B., \& Štulhofer, A. (2014). Correlates of men's sexual interest: A cross-cultural study. Journal of Sexual Medicine, 11(1), 154-164. https://doi.org/10.1111/jsm.12345

Carvalho, J., Campos, P., Carrito, M., Moura, C., Quinta-Gomes, A., Tavares, I., \& Nobre, P. (2021). The relationship between COVID19 confinement, psychological adjustment, and sexual functioning, in a sample of Portuguese men and women. Journal of Sexual Medicine, 18(7), 1191-1197. https://doi.org/10.1016/J.JSXM. 2021.04.007

Dewitte, M., Carvalho, J., Corona, G., Limoncin, E., Pascoal, P., Reisman, Y., \& Štulhofer, A. (2020). Sexual desire discrepancy: A position statement of the European Society for Sexual Medicine. Sexual Medicine, 8, 121-131. https://doi.org/10.1016/j.esxm.2020.02.008

Döring, N. (2020). How is the COVID-19 pandemic affecting our sexualities? An overview of the current media narratives and research hypotheses [Commentary]. Archives of Sexual Behavior, 49, 27652778. https://doi.org/10.1007/s10508-020-01790-z

ECDC. (2020). Resurgence of reported cases of COVID 19 in the EU/ EEA, the UK and EU candidate and potential candidate countries: 2 July 2020. https://www.ecdc.europa.eu/en/publications-data/ rapid-risk-assessment-resurgence-reported-cases-covid-19.

Elliot, A. J., Gable, S. L., \& Mapes, R. R. (2006). Approach and avoidance motivation in the social domain. Personality and Social Psychology Bulletin, 32(2), 378-391. https://doi.org/10.1177/01461 67205282153

Fernandes, N. (2020). Economic effects of coronavirus outbreak (COVID-19) on the world economy. SSRN Electronic Journal. https://doi.org/10.2139/ssrn.3557504

Ferreira, L. C., Narciso, I., Novo, R. F., \& Pereira, C. R. (2014). Predicting couple satisfaction: The role of differentiation of self, sexual desire and intimacy in heterosexual individuals. Sexual and Relationship Therapy, 29(4), 390-404. https://doi.org/10.1080/14681 994.2014.957498

Funk, J. L., \& Rogge, R. D. (2007). Testing the ruler with item response theory: Increasing precision of measurement for relationship satisfaction with the Couples Satisfaction Index. Journal of Family Psychology, 21(4), 572-583. https://doi.org/10.1037/0893-3200. 21.4.572

Gable, S. L. (2006). Approach and avoidance social motives and goals. Journal of Personality, 74(1), 175-222. https://doi.org/10.1111/j. 1467-6494.2005.00373.x

Gable, S. L., \& Impett, E. A. (2012). Approach and avoidance motives and close relationships. Social and Personality Psychology Compass, 6(1), 95-108. https://doi.org/10.1111/j.1751-9004.2011. 00405.x

Gable, S. L., \& Poore, J. (2008). Which thoughts count? Algorithms for evaluating satisfaction in relationships. Psychological Science, 19(10), 1030-1036. https://doi.org/10.1111/j.1467-9280. 2008.02195.x

Gewirtz-Meydan, A., \& Ayalon, L. (2019). Why do older adults have sex? Approach and avoidance sexual motives among older women and men. Journal of Sex Research, 56(7), 870-881. https://doi.org/ 10.1080/00224499.2018.1543644

Graham, J. W. (2012). Missing data: Analysis and design. Springer. https://doi.org/10.1007/978-1-4614-4018-5.
Hale, T., Anania, J., Angrist, N., Boby, T., Cameron-Blake, E., Ellen, L., Goldszmidt, R., Hallas, L., Kira, B., Luciano, M., Majumdar, S., Nagesh, R., Petherick, A., Phillips, T., Tatlow, H., Webster, S., Wood, A., \& Zhang, Y. (2021). Variation in government responses to COVID-19. Nature Human Behaviour, 5, 529-538. https://doi. org/10.1038/s41562-021-01079-8

Herbenick, D., Mullinax, M., \& Mark, K. (2014). Sexual desire discrepancy as a feature, not a bug, of long-term relationships: Women's self-reported strategies for modulating sexual desire. Journal of Sexual Medicine, 11(9), 2196-2206. https://doi.org/10.1111/jsm. 12625

Hinchliff, S., \& Gott, M. (2004). Intimacy, commitment, and adaptation: Sexual relationships within long-term marriages. Journal of Social and Personal Relationships, 21(5), 595-609. https://doi.org/10. 1177/0265407504045889

Holmes, E. A., O'Connor, R. C., Perry, V. H., Tracey, I., Wessely, S., Arseneault, L., Ballard, C., Christensen, H., Cohen Silver, R., Everall, I., Ford, T., John, A., Kabir, T., King, K., Madan, I., Michie, S., Przybylski, A. K., Shafran, R., Sweeney, A., \& Bullmore, E. (2020). Multidisciplinary research priorities for the COVID-19 pandemic: A call for action for mental health science. The Lancet Psychiatry, 7(6), 547-560. https://doi.org/10.1016/ S2215-0366(20)30168-1

Hunt, K., Adamson, J., \& Galdas, P. (2010). Gender and help-seeking: Towards gender-comparative studies. In E. Kuhlmann \& E. Annandale (Eds.), The Palgrave handbook of gender and healthcare (pp. 207-211). Palgrave Macmillan. https://doi.org/10.1057/97802 30290334 13

Ibarra, F. P., Mehrad, M., Di Mauro, M., Godoy, M. F. P., Cruz, E. G., Nilforoushzadeh, M. A., \& Russo, G. I. (2020). Impact of the COVID-19 pandemic on the sexual behavior of the population. The vision of the East and the West. International Brazilian Journal of Urology, 46(Suppl 1), 104-112. https://doi.org/10.1590/S16775538.IBJU.2020.S116

Impett, E. A., Gable, S. L., \& Peplau, L. A. (2005). Giving up and giving in: The costs and benefits of daily sacrifice in intimate relationships. Journal of Personality and Social Psychology, 89(3), 327-344. https://doi.org/10.1037/0022-3514.89.3.327

Impett, E. A., Peplau, L. A., \& Gable, S. L. (2005). Approach and avoidance sexual motives: Implications for personal and interpersonal well-being. Personal Relationships, 12(4), 465-482. https://doi. org/10.1111/j.1475-6811.2005.00126.x

Impett, E. A., Strachman, A., Finkel, E. J., \& Gable, S. L. (2008). Maintaining sexual desire in intimate relationships: The importance of approach goals. Journal of Personality and Social Psychology, 94(5), 808-823. https://doi.org/10.1037/0022-3514.94.5.808

Jacob, L., Smith, L., Butler, L., Barnett, Y., Grabovac, I., McDermott, D., Armstrong, N., Yakkundi, A., \& Tully, M. A. (2020). COVID19 social distancing and sexual activity in a sample of the British public. Journal of Sexual Medicine, 17, 1229-1236. https://doi. org/10.1016/j.jsxm.2020.05.001

Janssen, E., Macapagal, K. R., \& Mustanski, B. (2013). Individual differences in the effects of mood on sexuality: The revised Mood and Sexuality Questionnaire (MSQ-R). Journal of Sex Research, 50(7), 676-687. https://doi.org/10.1080/00224499.2012.684251

Kavanagh, M. M., \& Singh, R. (2020). Democracy, capacity, and coercion in pandemic response: COVID 19 in comparative political perspective. Journal of Health Politics, Policy and Law, 45, $997-$ 1012. https://doi.org/10.1215/03616878-8641530

Khaw, A. J., Burkholder, B., Salama, P., \& Dondero, T. J. (2000). HIV risk and prevention in emergency-affected populations: A review. Disasters, 24(3), 181-197. https://doi.org/10.1111/1467-7717. 00141

Kim, J. J., Muise, A., Barranti, M., Mark, K. P., Rosen, N. O., Harasymchuk, C., \& Impett, E. (2020). Are couples more satisfied 
when they match in sexual desire? New insights from response surface analyses. Social Psychological and Personality Science, 12(4), 487-496. https://doi.org/10.1177/1948550620926770

Kirana, P. S., Gudeloglu, A., Sansone, A., Fode, M., Reisman, Y., Corona, G., \& Burri, A. (2020). E-sexual health: A position statement of the European Society for Sexual Medicine. Journal of Sexual Medicine, 17(7), 1246-1253. https://doi.org/10.1016/j. jsxm.2020.03.009

Lane, S., MacDonald, N. E., Marti, M., \& Dumolard, L. (2018). Vaccine hesitancy around the globe: Analysis of three years of WHO/UNICEF joint reporting form data-2015-2017. Vaccine, 36(26), 3861-3867. https://doi.org/10.1016/j.vaccine.2018.03. 063

Lehmiller, J. J., Garcia, J. R., Gesselman, A. N., \& Mark, K. P. (2021). Less sex, but more sexual diversity: Changes in sexual behavior during the COVID-19 coronavirus pandemic. Leisure Sciences, 43, 295-304. https://doi.org/10.1080/01490400.2020.1774016

Li, G., Tang, D., Bin, S., Wang, C., Shen, Q., Xu, C., Geng, H., Wu, H., He, X., \& Cao, Y. (2020). Impact of the COVID-19 pandemic on partner relationships, sexual and reproductive health: A crosssectional online survey. Journal of Medical Internet Research, 22. https://doi.org/10.2196/20961

Li, W., Li, G., Xin, C., Wang, Y., \& Yang, S. (2020). Changes in sexual behaviors of young women and men during the Coronavirus disease 2019 outbreak: A convenience sample from the epidemic area. Journal of Sexual Medicine, 17, 1225-1228. https://doi.org/ 10.1016/j.jsxm.2020.04.380

Lopes, G. P., Vale, F. B. C., Vieira, I., da Silva Filho, A. L., Abuhid, C., \& Geber, S. (2020). COVID-19 and sexuality: Reinventing intimacy [Letter to the Editor]. Archives of Sexual Behavior, 49, 2735-2738. https://doi.org/10.1007/s10508-020-01796-7

Luijkx, R., Halman, L., Sieben, I., Brislinger, E., \& Quandt, M. (2016). European values in numbers. Brill. https://doi.org/10.1163/97890 04328525

Lykins, A. D., Janssen, E., \& Graham, C. A. (2006). The relationship between negative mood and sexuality in heterosexual college women and men. Journal of Sex Research, 43(2), 136-143. https:// doi.org/10.1080/00224490609552308

Mark, K. P., \& Lasslo, J. A. (2018). Maintaining sexual desire in longterm relationships: A systematic review and conceptual model. Journal of Sex Research, 55(4-5), 563-581. https://doi.org/10. 1080/00224499.2018.1437592

Mark, K. P., Herbenick, D., Fortenberry, D., Sanders, S., \& Reece, M. (2014). The object of sexual desire: Examining the "What" in "What do you desire?" Journal of Sexual Medicine, 11(11), 2709-2719. https://doi.org/10.1111/jsm.12683

Mazza, M., Marano, G., Lai, C., Janiri, L., \& Sani, G. (2020). Danger in danger: Interpersonal violence during COVID-19 quarantine. Psychiatry Research, 289, 113046. https://doi.org/10.1016/j.psych res.2020.113046

Miranda, E. P., Nascimento, B., Torres, L. O., Glina, S., Carvalho, J., \& Pascoal, P. M. (2020). Challenges in the practice of sexual medicine in the time of COVID-19 in Portugal. Journal of Sexual Medicine, 17(7), 1212-1215. https://doi.org/10.1016/j.jsxm.2020. 05.013

Morris, N. P. (2020). Staying apart during a pandemic. JAMA Internal Medicine, 180, 1047-1048. https://doi.org/10.1001/jamaintern med.2020.2505

Muise, A., Boudreau, G. K., \& Rosen, N. O. (2017). Seeking connection versus avoiding disappointment: An experimental manipulation of approach and avoidance sexual goals and the implications for desire and satisfaction. Journal of Sex Research, 54(3), 296-307. https://doi.org/10.1080/00224499.2016.1152455

Muise, A., Impett, E. A., \& Desmarais, S. (2013). Getting it on versus getting it over with: Sexual motivation, desire, and satisfaction in intimate bonds. Personality and Social Psychology Bulletin, 39(10), 1320-1332. https://doi.org/10.1177/0146167213490963

Nimbi, F. M., Tripodi, F., Rossi, R., Navarro-Cremades, F., \& Simonelli, C. (2020). Male sexual desire: An overview of biological, psychological, sexual, relational, and cultural factors influencing desire. Sexual Medicine Reviews, 8(1), 59-91. https://doi.org/10. 1016/j.sxmr.2018.12.002

Pereira, T. J., Machado, P. P. P., \& Peixoto, M. M. (2019). Sexual and relationship satisfaction: The role of perceived (non)problematic sexual desire discrepancy in gay and heterosexual men. Journal of Sex and Marital Therapy, 45(2), 103-113. https://doi.org/10.1080/ 0092623X.2018.1488323

Pfefferbaum, B., \& North, C. S. (2020). Mental health and the Covid19 pandemic. New England Journal of Medicine, 383, 510-512. https://doi.org/10.1056/nejmp2008017

Prime, H., Wade, M., \& Browne, D. T. (2020). Risk and resilience in family well-being during the COVID-19 pandemic. American Psychologist, 75(5), 631-643. https://doi.org/10.1037/amp0000660

Roesch, E., Amin, A., Gupta, J., \& García-Moreno, C. (2020). Violence against women during covid-19 pandemic restrictions. British Medical Journal, 369. https://doi.org/10.1136/bmj.m1712

Rosen, N. O., Bailey, K., \& Muise, A. (2018). Degree and direction of sexual desire discrepancy are linked to sexual and relationship satisfaction in couples transitioning to parenthood. Journal of Sex Research, 55(2), 214-225. https://doi.org/10.1080/00224499. 2017.1321732

Ross, M. W., Månsson, S. A., Daneback, K., Cooper, A., \& Tikkanen, R. (2005). Biases in internet sexual health samples: Comparison of an internet sexuality survey and a national sexual health survey in Sweden. Social Science and Medicine, 61(1), 245-252. https:// doi.org/10.1016/j.socscimed.2005.01.019

Sanchez, D. T., Moss-Racusin, C. A., Phelan, J. E., \& Crocker, J. (2011). Relationship contingency and sexual motivation in women: Implications for sexual satisfaction. Archives of Sexual Behavior, 40(1), 99-110. https://doi.org/10.1007/s10508-009-9593-4

Schiavi, M. C., Spina, V., Zullo, M. A., Colagiovanni, V., Luffarelli, P., Rago, R., \& Palazzetti, P. (2020). Love in the time of COVID19: Sexual function and quality of life analysis during the social distancing measures in a group of Italian reproductive-age women. Journal of Sexual Medicine, 17, 1407-1413. https://doi.org/10. 1016/j.jsxm.2020.06.006

Schoenfeld, E. A., Loving, T. J., Pope, M. T., Huston, T. L., \& Štulhofer, A. (2017). Does sex really matter? Examining the connections between spouses' nonsexual behaviors, sexual frequency, sexual satisfaction, and marital satisfaction. Archives of Sexual Behavior, 46(2), 489-501. https://doi.org/10.1007/s10508-015-0672-4

Sprecher, S., \& Cate, R. M. (2004). Sexual satisfaction and sexual expression as predictors of relationship satisfaction and stability. In J. H. Harvey, A. Wenzel, \& S. Sprecher (Eds.), The handbook of sexuality in close relationships (pp. 235-256). Erlbaum.

Štulhofer, A., Ferreira, L. C., \& Landripet, I. (2013). Emotional intimacy, sexual desire, and sexual satisfaction among partnered heterosexual men. Sexual and Relationship Therapy, 29(2), 229-244. https://doi.org/10.1080/14681994.2013.870335

Štulhofer, A., Jurin, T., Graham, C., Janssen, E., \& Træen, B. (2020). Emotional intimacy and sexual well-being in aging European couples: A cross-cultural mediation analysis. European Journal of Ageing, 17(1), 43-54. https://doi.org/10.1007/s10433-019-00509-x

Træen, B., Hald, G. M., Graham, C. A., Enzlin, P., Janssen, E., Kvalem, I. L., Carvalheira, A., \& Štulhofer, A. (2017). Sexuality in older adults (65+) - An overview of the literature, part 1: Sexual function and its difficulties. International Journal of Sexual Health, 29(1), 1-10. https://doi.org/10.1080/19317611.2016.1224286

Turban, J. L., Keuroghlian, A. S., \& Mayer, K. H. (2020). Sexual health in the SARS-CoV-2 era. Annals of Internal Medicine. https://doi. org/10.7326/M20-2004 
Usher, K., Bhullar, N., Durkin, J., Gyamfi, N., \& Jackson, D. (2020). Family violence and COVID-19: Increased vulnerability and reduced options for support. International Journal of Mental Health Nursing, 29(4), 549-552. https://doi.org/10.1111/inm. 12735

Wisner, B., \& Adams, J. (Eds.). (2002). Environmental health in emergencies and disasters: A practical guide. World Health Organization.

Yuksel, B., \& Ozgor, F. (2020). Effect of the COVID-19 pandemic on female sexual behavior. International Journal of Gynecology and Obstetrics, 150(1), 98-102. https://doi.org/10.1002/ijgo.13193

Zhang, W. R., Wang, K., Yin, L., Zhao, W. F., Xue, Q., Peng, M., Min, B. Q., Tian, Q., Leng, H. X., Du, J. L., Chang, H., Yang, Y., Li,
W., Shangguan, F. F., Yan, T. Y., Dong, H. Q., Han, Y., Wang, Y. P., Cosci, F., \& Wang, H. X. (2020). Mental health and psychosocial problems of medical health workers during the COVID-19 epidemic in China. Psychotherapy and Psychosomatics, 89(4), 242-250. https://doi.org/10.1159/000507639

Publisher's Note Springer Nature remains neutral with regard to jurisdictional claims in published maps and institutional affiliations. 